\title{
Reduction in bronchodilation following a deep inhalation is poorly related to airway inflammation in asthma
}

\author{
F. Pacini*, M. Filippelli**, R. Duranti**, E. Rosi**, I. Romagnoli**, M. Grazzini*, \\ L. Stendardi*, G. Misuri*, G. Scano***
}

Reduction in bronchodilation following a deep inhalation is poorly related to airway inflammation in asthma? F. Pacini, M. Filippelli, R. Duranti, E. Rosi, I. Romagnoli, M. Grazzini, L. Stendardi, G. Misuri, G. Scano. (C) ERS Journals Ltd 1999.

ABSTRACT: In patients with bronchial asthma, forced expiratory flows are differently sensitive to a previous volume history. A reduced ability of a deep inhalation (DI) to dilate obstructed airways has been hypothesized to be a physiological marker for the degree of airway responsiveness and to relate to the presence and magnitude of inflammation in the lung, even in mild stable asthma. However, there are at present doubts as to whether functional changes could be used as a substitute for airway inflammation studies.

In order to investigate the interrelations among airway inflammation, bronchial hyperresponsiveness and effects of volume history, 58 consecutive asthmatics with mild to moderate asthma were studied. The effects of DI were assessed as the isovolumic ratio of flows from forced expiratory manoeuvres started from maximal (M) or partial (P) lung inflation. Airway inflammation was assessed by using induced sputum. Sputum was analysed for total and differential cell counts, and levels of eosinophil cationic protein (ECP) which reflects eosinophil activation. Airway responsiveness was assessed as the provocative concentration of histamine which caused a $20 \%$ fall in forced expiratory volume in one second (FEV1) from control (PC20).

The $M / P$ ratio was significantly related to $\operatorname{ECP}(r=-0.31, p<0.03)$ and eosinophils $(r=-0.29, p<0.03), F E V 1 / v i t a l$ capacity $(\mathrm{VC})(\mathrm{r}=0.32 ; \mathrm{p}<0.01)$, clinical score $(r=-0.33$; $p<0.03)$ and age $(r=-0.41 ; p<0.0001)$. In a stepwise multiple regression analysis including age, score, baseline lung function, ECP, number of eosinophils and the response to $\beta_{2}$-agonist, age $(\mathbf{p}<0.037)$ predicted a small amount of the variance in $M / P$ ratio $\left(r^{2}=0.12\right)$.

It is concluded that volume history response is substantially independent of both sputum outcomes (inflammatory cell number and eosinophil cationic protein) and bronchial hyperresponsiveness; rather it seems to be associated with anthropometric characteristics. Functional aspects do not provide information on eosinophilic, probably central, airway inflammation.

Eur Respir J 1999; 14: 1055-1060.

In patients with bronchial asthma maximal expiratory flow is affected by a deep inhalation (DI) varying from an increase, to no effect, to a decrease in expiratory flow. These changes relate to the site and mechanism of the obstructive process [1]. A reduction in bronchodilation following a DI has been shown to be positively related to the severity of airway inflammation [2]. An increase in the bronchodilator effect of a DI, after corticosteroid administration, has consistently been reported [2-4]. Furthermore, the bronchodilator effect of DI is inversely related to the degree of responsiveness to a subsequent methacholine challenge in mild asthma [5]. Thus, several lines of evidence suggest that the blunting of the dilator effect of DI during obstruction could serve as a physiological marker for the degree of airway responsiveness and may relate to the presence and magnitude of inflammation in the lung even in mild stable asthma [2].

This hypothesis is based either on findings in small animals [6] or on a few observations in asthmatics [2] in whom the same effect of DI, i.e., a decrease in expiratory flow, was shared by patients with the highest and the low-
*Fondazione Don C. Gnocchi ONLUS, Pozzolatico and **Dept of Internal Medicine-Section of Pneumology, University of Florence, Firenze, Italy.

Correspondence: G. Scano

Istituto di Medicina Interna ed Immunoallergologia

Viale G.B. Morgagni 85

Careggi 50134

Firenze

Italy

Fax: 39055412867

Keywords: Airway inflammation asthma

deep inhalation

eosinophils

hyperresponsiveness

Received: December 311998

Accepted after revision July 181999 est level of eosinophils in bronchoalveolar lavage fluid (BALF).

At present, studies of airway inflammation are limited to BALF or sputum outcomes. To assess airway inflammation this study used sputum induction. Recent studies have proposed the analysis of induced sputum as a reliable and noninvasive method for the investigation, identification and monitoring of airway inflammation in patients with asthma [7-10]. Similar to findings from bronchial biopsies and BALF examinations, the sputum of patients with asthma is characterized by an increased proportion of eosinophils and higher level of eosinophil cationic protein (ECP) [9]. Eosinophils and their activation products such as ECP, have been considered crucial elements in the pathogenesis of asthma and therefore directly or indirectly involved in functional alterations of the bronchial tree. Nonetheless, are well aware of the fact that inflammation is more than just cell infiltration or mediator release and that this study suffers from limitations imposed by techniques which represent only a part of the scenario of airway inflammation. 
The primary goal of this study was to establish the interrelationships among airway inflammation, assessed by sputum outcomes, reduction in bronchodilation following a DI and bronchial hyperresponsiveness (BHR), in a cross sectional study of asthma patients. The effects of DI were assessed from the ratio of flows from successively performed forced expiratory manoeuvres started from full or partial lung inflation.

\section{Methods}

Fifty-eight consecutive patients (19 males and 39 females) aged 11-75 (median 39) yrs with stable chronic bronchial asthma, according to the criteria of the National Heart, Lung and Blood Institute [11], participated in the study. Asthma was characterized by a history of episodes of dyspnoea with wheezing and $>15 \%$ forced expiratory volume in one second (FEV1) increase from baseline after inhalation of $100 \mu \mathrm{g}$ of a $\beta_{2}$-bronchodilator agent and by $\mathrm{BHR}$ to histamine, the provocative concentration of histamine causing $20 \%$ fall in FEV1 (PC20) being $<8 \mathrm{mg} \cdot \mathrm{mL}^{-1}$. Subjects sensitized to pollens were studied out of the relevant season. The duration of disease ranged from 1 month to $40 \mathrm{yrs}$. All patients were in a clinically stable condition at the time of the study and had been receiving daily inhaled corticosteroids $\left(500-1,000 \mu \mathrm{g} \cdot \mathrm{day}^{-1}\right)$ and bronchodilators p.r.n. Bronchodilators were withheld for at least $12 \mathrm{~h}$ before the study. All subjects had been free from acute respiratory infections for the preceding 4 weeks. Informed consent was given by each subject and the study was approved by the Local Ethics Committee.

\section{Clinical scores}

Asthma severity was assessed by a modified version of the asthma severity scores (ASS) proposed by BROOKS et al. [12]. Possible scores ranged 0-20. ASS was based on: 1) frequency of attacks of wheezing and/or chest tightness that occurred during an average day, score from 0-4 (0: none; 1: at least one; 2: two; 3: three or four; 4: five or more); 2) frequency of attacks of wheezing and/or chest tightness that occurred at night, score from 0-4 (0: none; 1: $1-2 \cdot \mathrm{yr}^{-1} ; 2$ : monthly; 3: weekly; 4: daily); 3) chronic exertional dyspnoea (from modified the UK Medical Research Council dyspnoea scale [13]: score from 0 (no breathlessness) to 4 (breathlessness during dressing or undressing); 4) therapy that the patient required to control asthma, score from $0-4\left(0\right.$ : none; 1 : $\beta_{2}$-agonist bronchodilators $1-2$ times $\cdot \mathrm{yr}^{-1} ; 2$ : intermittently only; 3 : daily; 4 : in association with inhaled corticosteroids); 5) frequency of cough, score from 0-4 (0: no cough; 1: occasional cough but seriously disturbing; 2 : quite troublesome during attacks only; 3: very troublesome and frequent; 4 : distressing most of the day or night).

\section{Study design}

In this cross-sectional study patients with stable asthma were referred from the Institute of Allergology and Clinical Immunology of the University of Florence. Patients attended the laboratory twice. In the first visit spirometry, flow $\left(V^{\prime}\right)$ /volume $(V)$ curves and histamine challenge test were carried out. At the second visit reversibility of bronchoobstruction was assessed and sputum was induced.

\section{Lung function}

Baseline pulmonary function testing was performed by measuring static and dynamic lung volumes with a watersealed spirometer (Pulmonet Godart; SensorMedics Corp., Yorba Linda, CA, USA), as previously reported [14]. The normal values for lung volumes used here are those proposed by the European Community for Coal and Steel [15].

Forced expiratory volume and flow volume curves were recorded simultaneously, at the mouth through a pneumotachograph (Fleisch type 3; SensorMedics Corp., Yorba Linda, CA, USA) linear up to $12 \mathrm{~L} \cdot \mathrm{s}^{-1}$ and volume was obtained by electrical integration of the flow signal after careful elimination' of the drift of the integgrator. The flow volume curves were stored on a personal computer and then printed by means of a laser printer. The flow volume manoeuvres were performed as follows: the seated patients maintained tidal breathing for 2-3 min, avoiding any deep breaths or coughs; from an end tidal inspiration then exhaled forcefully to residual volume to generate the partial flow volume curve $(\mathrm{P})$ after which each subject inhaled rapidly to total lung capacity (TLC) and immediately performed a maximal forced expiratory manoeuvre (M). The ratio of $V^{\prime} \max$ on the complete and partial curves at isovolumic points, as recorded by the spirometer and measured at $60 \%$ of vital capacity (VC) from TLC, was expressed as the $\mathrm{M} / \mathrm{P}$ ratio [16]. The volume from which the partial forced expiratory manoeuvre starts, needs to be carefully standardized: deviations $>30 \%$ control end-inspiratory tidal volume were excluded. Only $V^{\prime} / V$ curves with sharp peak flow were retained for analysis. Reproducible maxi$\mathrm{mal} /$ partial combined manoeuvres for each subject were obtained.

\section{Sputum analysis}

Induction of sputum was performed according to the method of PIN et al. [7]. Briefly, 10 min after fenoterol inhalation $(200 \mu \mathrm{g})$, hypertonic saline was nebulized with an ultrasonic nebulizer (Fisoneb; Fisons Corp., Rochester, NY, USA) and was inhaled for 5 min periods up to 20 min. The concentration of saline was increased at intervals of $10 \mathrm{~min}$ from 3 to $4 \%$. FEV1 was measured every 5 min during inhalation of hypertonic saline solution. The sputum induction procedure did not cause troublesome symptoms and the FEV1 did not decrease by $>20 \%$ in any subject. Every 5 min subjects were asked to try to cough sputum into a Petri dish and to collect saliva in a separate container. Cytological analysis and ECP measurement were performed according to the method of PIN et al. [7] as previously described $[17,18]$ : two or three plugs free of salivary contamination were suspended in dithiothreitol (DTT) solution $(0.1 \%)$ and incubated for $30 \mathrm{~min}$ at $37^{\circ} \mathrm{C}$ for slide making. Cells were centrifuged at $400 \times g$ for $10 \mathrm{~min}$ and then resuspended in saline. Three sputum slides were then prepared for cytological examination by cytocentrifugation. Cells were air dried and stained with May-Grünwald Giemsa stain. Cell differentials were determined by counting 200 nonsquamous cells on each sputum slide. The volume of the remaining portion of sputum samples was determined and an equal volume of DTT $(0.1 \%)$ was added. The samples were mixed by vortex and incubated at $37^{\circ} \mathrm{C}$ for $20 \mathrm{~min}$. The samples were then centrifuged at $1,000 \times g$ for $10 \mathrm{~min}$. The supernatants 
Table 1. - Anthropometric, clinical and functional data

\begin{tabular}{|c|c|c|c|c|c|c|c|c|c|c|c|}
\hline \multirow[b]{2}{*}{ Patients } & \multirow[b]{2}{*}{$\begin{array}{l}\text { Sex } \\
\mathrm{M} / \mathrm{F}\end{array}$} & \multirow[b]{2}{*}{$\begin{array}{l}\text { Age } \\
\text { yrs }\end{array}$} & \multirow{2}{*}{$\begin{array}{c}\text { Duration } \\
\text { of disease } \\
\text { yrs }\end{array}$} & \multirow{2}{*}{$\begin{array}{l}\text { Clinical } \\
\text { score } \\
\text { a.u. }\end{array}$} & \multirow[b]{2}{*}{$\begin{array}{l}\mathrm{VC} \\
\% \text { pred }\end{array}$} & \multirow[b]{2}{*}{$\begin{array}{c}\text { FRC } \\
\% \text { pred }\end{array}$} & \multirow[b]{2}{*}{$\begin{array}{c}\text { TLC } \\
\% \text { pred }\end{array}$} & \multicolumn{2}{|c|}{ FEV1 } & \multirow[b]{2}{*}{$\begin{array}{c}\mathrm{FEV} 1 / \mathrm{VC} \\
\%\end{array}$} & \multirow[b]{2}{*}{$\mathrm{M} / \mathrm{P}$} \\
\hline & & & & & & & & $\begin{array}{l}\text { Control } \\
\% \text { pred }\end{array}$ & $\begin{array}{l}\beta_{2} \\
\%\end{array}$ & & \\
\hline $\mathrm{D}$ & $19 / 39$ & $39 \pm 16$ & $9.5 \pm 10.2$ & $10.9 \pm 4.4$ & 101.1 & $104.9=$ & 104. & 84.2 & $14.7 \pm 1$ & 68.6 & $1.1=$ \\
\hline $\begin{array}{l}\text { Median } \\
\text { (range) }\end{array}$ & & $\begin{array}{c}37 \\
(11-75)\end{array}$ & $\begin{array}{c}5 \\
(0.1-40)\end{array}$ & $\begin{array}{c}11 \\
(3-19)\end{array}$ & $\begin{array}{c}102.2 \\
(61.2-139.4)\end{array}$ & $\begin{array}{c}102.4 \\
(65.3-153.2)\end{array}$ & $\begin{array}{c}103.5 \\
(68.3-132.7)\end{array}$ & $\begin{array}{c}85.9 \\
(32.5-117.8)\end{array}$ & $\begin{array}{c}14 \\
(10.6-14.7)\end{array}$ & $\begin{array}{c}67.4 \\
(36.4-92.2)\end{array}$ & $\begin{array}{c}1.0 \\
(0.5-2.3)\end{array}$ \\
\hline
\end{tabular}

M: male; F: female; a.u.: arbitrary units; VC: vital capacity; FRC: functional residual capacity (Helium technique); TLC: total lung capacity; FEV1: forced expiratory volume in one second; $\beta_{2}$ : FEV1 after $\beta_{2}$-agonist as percentage of control; M/P: maximal to partial flow at $40 \%$ of VC.

were aspirated and frozen at $-70^{\circ} \mathrm{C}$ for later ECP analysis. ECP was assessed by a fluoroenzymaticimmunoassay (FEIA) (CAP ECP FEIA Kabi Pharmacia; Kabi Pharmacia, Uppsala, Sweden). Anti-ECP, covalently coupled to immuno-CAP (a cylindrical support which contains a cellulose-carrier to which the antibody anti-ECP is bound), reacted with the ECP in the specimens. After washing, enzyme-labelled antibodies against ECP were added to form a complex. After incubation, unbound enzyme antiECP was washed away and the bound complex was then incubated with a developing agent. After stopping the reaction, the fluorescence of the eluate was measured in Fluoro-Count 96 (Kabi Pharmacia). The sensitivity of this technique is $<0.5 \mathrm{mg} \cdot \mathrm{L}^{-1}$. ECP was determined in duplicate.

\section{Bronchial challenge}

Each patient was administered a histamine aerosol inhalation test using the tidal breathing method [19]. Increasing concentrations of histamine-acid phosphate in normal phosphate buffered saline (prepared by the University Hospital Pharmacy, University of Florence, Italy) were inhaled from a DeVilbiss 646 nebulizer (DeVilbiss Co., Somerset, PA, USA) resulting in an output of 0.13 $\mathrm{mL} \cdot \mathrm{min}^{-1}$. With this method $4 \mathrm{~mL}$ of solution were placed in the nebulizer and inhalation continued during tidal breathing for $2 \mathrm{~min}$. Histamine solution was stored at $4{ }^{\circ} \mathrm{C}$ and nebulized at room temperature. Normal phosphate buffered saline was inhaled first, followed at 5-min intervals by histamine in two-fold increasing concentrations from $0.031-16 \mathrm{mg} \cdot \mathrm{mL}^{-1}$. The test was stopped when the histamine patients FEV1 fell by $20 \%$. From the log doseresponse curve, the concentration of histamine required to produce the PC20 was noted.

\section{Statistical analysis}

The statistical analysis carried out considers the dependency of a variable (e.g. the degree of DI effect) on a series of independent variables: inflammatory cell count and activation; pulmonary function (inspiratory vital capacity
(IVC), FEV, and FEV1/VC); clinical data (age, score); and BHR (PC20). In this way the effect of each variable on DI was evaluated independently of the effect of all other variables. Single regression analysis was performed by Pearson's or Spearman's single correlation coefficients when appropriate. In multiple regression analysis a rule of thumb is to limit the number of variables as a function of the number of patients (n:10) [20]. Thus multiple regression analysis with stepwise selection of the independent variables was carried out by relating the $\mathrm{M} / \mathrm{P}$ ratio to clinical, variables, functional variables and sputum outcomes.

PC20 and ECP were $\log$ transformed for statistical evaluation. A p-value of $<0.05$ was considered as the threshold of statistical significance. Values are given as mean \pm SD, unless otherwise noted.

\section{Results}

Anthropometric and clinical characteristics of the patients are shown in tables 1 and 2. On average, patients were mildly obstructed with a level of hyperresponsiveness varying from mild to moderate to severe. As shown in table 1 the mean $\mathrm{M} / \mathrm{P}$ value was $1.1 \pm 0.36$, range $0.5-$ 2.30 .

Sputum cellular and biochemical characteristics are shown in table 2. It is evident from the table that both eosinophils and ECP but not lymphocytes were above the normal range of the authors' laboratory $(0.6-3.2 \%,<140$ $\mu \mathrm{g} \cdot \mathrm{mL}^{-1}, 0.7-2.4 \%$, respectively) $[17,18]$.

Individual relationships between $\mathrm{M} / \mathrm{P}$ ratio, $\log \mathrm{ECP}$ and eosinophils, score and age are shown in figure 1. It can be seen in the figure that the large proportion of patients with normal eosinophils exhibited a variable $\mathrm{M} / \mathrm{P}$ ratio $(0.5-$ 2.5) while a normal M/P ratio (0.8-1.2) [21] was shared by patients who covered the whole range of eosinophil in sputum.

$\mathrm{M} / \mathrm{P}$ also related to $\mathrm{FEV} 1 / \mathrm{VC}(\mathrm{p}<0.01 ; \mathrm{r}=0.32)$ but not to $\mathrm{PC} 20(\mathrm{p}=0.3)$ or $\beta_{2}$-bronchodilator response $(\mathrm{p}=0.2)$.

The results of stepwise multiple regression analysis show (table 3$)$ that age $\left(\mathrm{p}<0.0376 ; \mathrm{r}^{2}=0.12\right)$ predicted a small proportion of the $\mathrm{M} / \mathrm{P}$ variance, the regression equation being: $\mathrm{M} / \mathrm{P}=1.51-0.009$ age.

Table 2. - Sputum cellular count, eosinophil cationic protein (ECP) level and bronchial hyperresponsiveness

\begin{tabular}{|c|c|c|c|c|c|c|}
\hline Patients & $\begin{array}{c}\text { Macrophages } \\
\%\end{array}$ & $\begin{array}{c}\text { Lymphocytes } \\
\%\end{array}$ & $\begin{array}{c}\text { Eosinophils } \\
\%\end{array}$ & $\begin{array}{c}\text { Neutrophils } \\
\%\end{array}$ & $\begin{array}{l}\mathrm{ECP} \\
\mu \mathrm{g} \cdot \mathrm{L}^{-1}\end{array}$ & $\begin{array}{c}\mathrm{PC} 20 \\
\mathrm{mg} \cdot \mathrm{mL}^{-1}\end{array}$ \\
\hline Mean \pm SD & $46.5^{*}$ & $0.3 \pm 0.5$ & $19.9 \pm 24.2$ & $16.7^{*}$ & $1018.3 \pm 2219.7$ & $0.75^{*}$ \\
\hline Median (range) & $52.4(7.7-96)$ & $0.1(0.0-1.8)$ & $6.2(0-83)$ & $20.6(0.4-77.1)$ & $321.6(6.4-14580)$ & $0.94(0.06-7.6)$ \\
\hline
\end{tabular}

PC20: provocative concentration of histamine causing a $20 \%$ decrease in forced expiratory volume in one second (FEV1) from control. *: geometric mean. 
Table 3. - Multiple regression analyses in the 58 patients

\begin{tabular}{lllll}
\hline & \multicolumn{1}{c}{ Estimate } & \multicolumn{1}{c}{ SEM } & T-statistic & p-value \\
\hline Independent variables & & & & \\
Constant & 2.84594 & 0.767106 & 3.70997 & 0.0012 \\
Age & -0.0112923 & 0.00500151 & -2.25778 & 0.0342 \\
FEV1/VC & -0.010046 & 0.00745876 & -1.34687 & 0.1917 \\
$\beta_{2} \%$ control & -0.00357413 & 0.00833664 & -0.428726 & 0.6723 \\
Log ECP & -0.0788127 & 0.107816 & -0.730991 & 0.4725 \\
Eosinophils & -0.0026851 & 0.00310253 & -0.865455 & 0.3961 \\
Score & -0.0250286 & 0.0150014 & -1.66842 & 0.1094 \\
Stepwise analysis & & & \\
Independent variables & & & \\
Constant & 1.51451 & 0.177585 & 8.52834 & 0.00000 \\
Age & -0.00943459 & 0.00431333 & -2.18731 & 0.0376 \\
\hline
\end{tabular}

In all analyses the dependent variable was the maximal $(\mathrm{M})$ to partial $(\mathrm{P})$ lung inflation ratio. $\mathrm{r}^{2}=0.12 \%$. Regression equation: $\mathrm{M} / \mathrm{P}=1.51-0.009$ age. FEV1: forced expiratory volume in one second; VC: vital capacity; ECP: eosinophil cationic protein.

\section{Discussion}

In patients with stable, mild to moderate, chronic asthma this study was unable to show clinically meaningful interrelationships among $\mathrm{M} / \mathrm{P}$ ratio, $\mathrm{BHR}$ and sputum outcomes, the latter reflecting airway inflammation. Instead, age predicted a small amount of the variability in the M/P ratio.

In patients with asthma, the predominant tendency is that spontaneous obstruction most often worsens after a deep inhalation [22], the more severe the degree of spontaneous obstruction, the greater the bronchoconstrictor
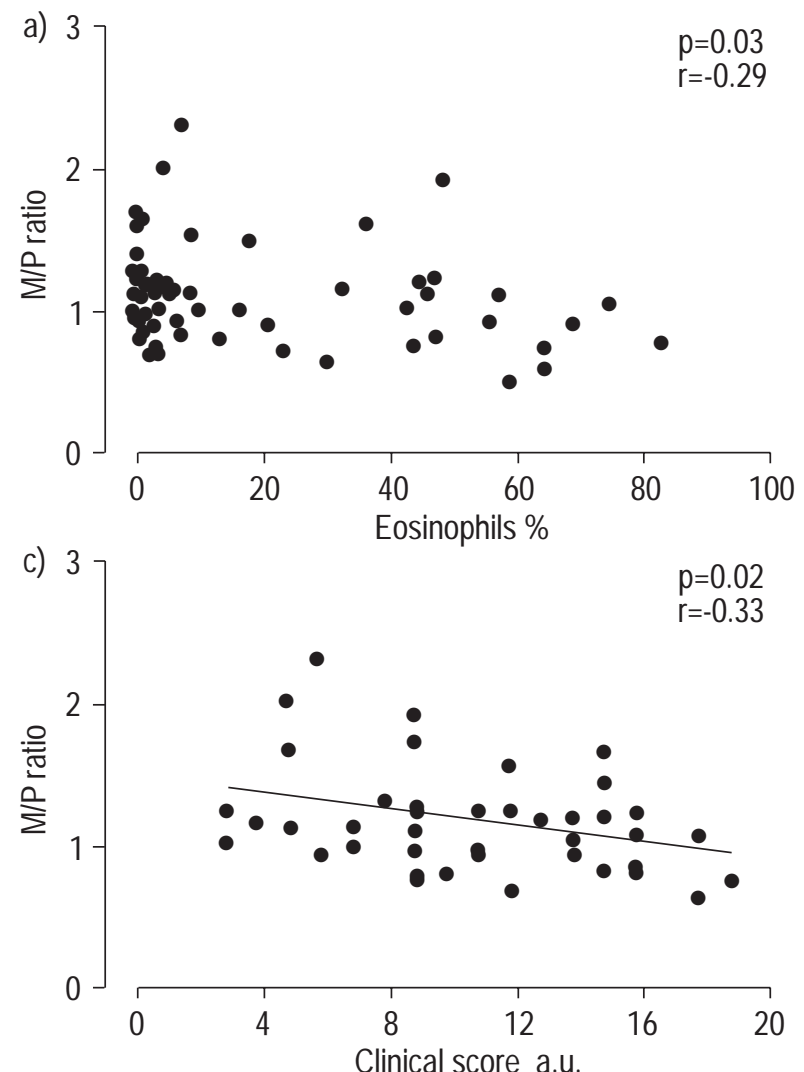

effect of DI. At variance to this, quite consistently [23, 24], M/P ratios increase during induced constriction. The mechanical basis for a constrictor effect of DI can be explained by disparities between the hysteresis of airways and parenchyma as proposed by Froeb and MEAD [25]. Both airways and parenchyma have hysteresis and both are stretched during a DI. When hysteresis of parenchyma exceeds that of the airways, airways will be smaller after deflation than before inflation when compared at isovolume. On the other hand, if hysteresis of airways, which is in direct proportion to smooth muscle tone, exceeds that of parenchyma, airways will be larger after a DI. Lim et al. [24] have interpreted the variable volume history effect as representing predominant smooth muscle activity associated with predominant airway hysteresis in patients with mild asthma during acutely induced obstruction, and predominant inflammatory activity, perhaps more peripherally, associated with predominant parenchyma hysteresis during severe spontaneous obstruction. A predictable diminution in the constrictor effects of a DI as spontaneous obstruction abates has been shown, implying that an inflammatory process in the periphery of the lung accounts for the obstruction in spontaneous asthma rather than mere constriction of smooth muscle in conducting airway [3]. In other words, volume history ratio decreases in asthma as inflammatory obstruction increases and rises as overall lung function improves with antiinflammatory therapy [2-4].

More recent studies have shown that peripheral airway wall inflammation and oedema by expanding peribronchial
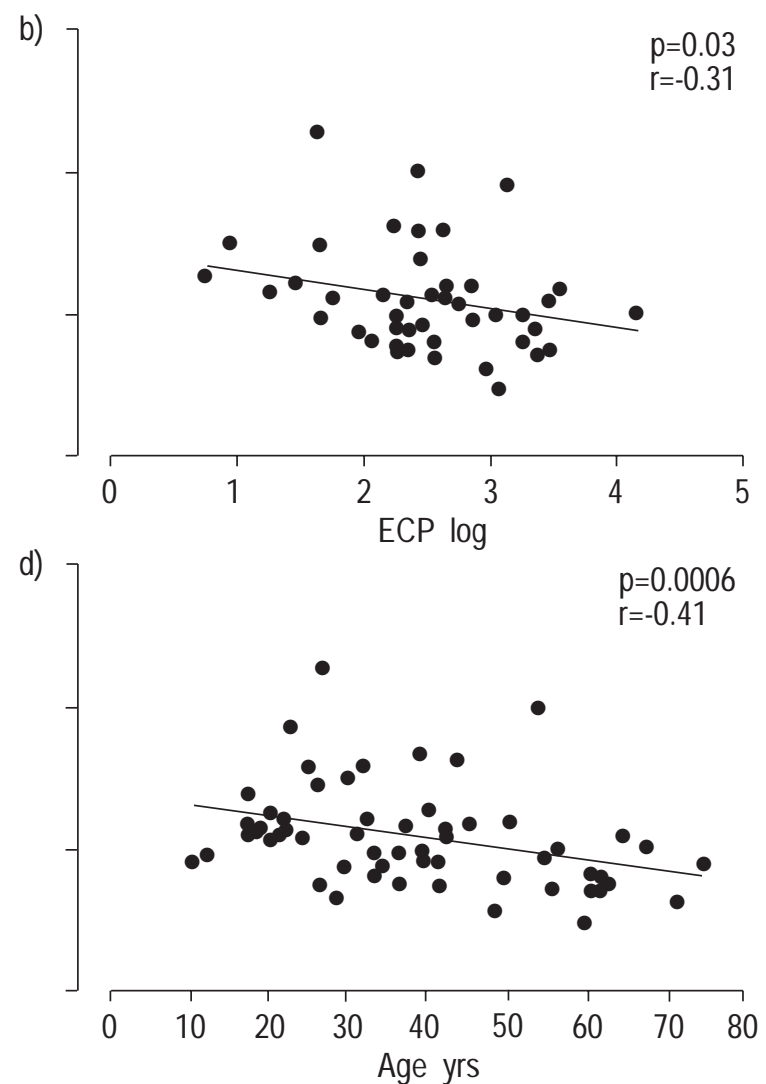

Fig. 1. - Individual data points of the relationships of maximal (M) to partial (P) lung inflation ratio versus a) sputum eosinophils, b) sputum eosinophil cationic protein (ECP), c) clinical score (in arbitrary units (a.u.)) and d) age. Regression lines are shown for b), c) and d). The data for a) were not normally distributed, and therefore analysis was performed using Spearman's single correlation coefficient. 
space and unlinking the airways from the parenchyma [26], may impair the deep breath effect and explain a low $\mathrm{M} / \mathrm{P}$ ratio [27]. In addition, the adventitial thickening would tend to diminish the tidal forces to which the smooth muscles are subjected. In this case the tidal stretch would be small, the active force would be large and the underlying contractile state would tend to the one that pertains in steady-state isometric condition. The latter would allow the muscle to become stiff and insensitive to the influences of deep inspiration [28].

Thus it seems that blunting of the dilator volume history response during obstruction serves as a physiological marker for the degree of airway responsiveness and might relate to the presence and magnitude of inflammation in the lung even in mild stable asthma. Direct evidence was provided by Puiss et al. [2] who showed that DI bronchodilation at baseline in mild stable asthmatic subjects related inversely to bronchoalveolar lavage (BAL) derived mediators and eosinophils. Moreover, INGENITO et al. [6] found a good relationship between pattern of diminished volume history and both BAL total protein concentration and specific pattern of severity of lung inflammation, assessed pathologically in antigen challenged animals.

The present results, however, seem not to be in line with the above possibilities. The following is an attempt to explain the discrepancy in the current findings and those of other researchers: 1) Methodology. Different methods were used in the present study, utilizing sputum outcomes rather than BAL as in the study by PLiss et al. [2]. A number of studies have recently proposed that induced sputum analysis is reliable and noninvasive for investigating and monitoring airway inflammation in asthmatic patients [710, 17, 18]. Similar to findings from bronchial biopsies and BALF examinations, the sputum of patients with asthma is characterized by an increased proportion of eosinophils and higher level of ECP [29]. The repeatability of sputum specific cell counts is high [30] while the repeatability of soluble markers in BAL is poor [31]. High repeatability depends on a high signal to noise ratio which is high in sputum and low in BAL [10]. The above considerations suggest that sputum is preferable to invasive techniques, such as BAL, for studies devised to assess airway inflammation. Nevertheless, the authors are aware of the fact that the differences in techniques may be involved in the reported discrepancies. The cellular composition of induced sputum may reflect events in larger airways while BAL seems mostly to reflect peripheral events.

Therefore, it can be argued that central airway inflammation as reflected by sputum outcomes may not correlate to $\mathrm{M} / \mathrm{P}$ ratio but this does not mean that $\mathrm{M} / \mathrm{P}$ ratios do not reflect airway inflammation.

2) Statistical analysis. Although volume history was found to relate to eosinophil count in BAL from 11 asthmatics [2], the same effect of DI, a decrease in expiratory flow rate, was shared by 5 patients who covered the range of eosinophil and albumin values in BAL (see fig. 1 in [2]). Moreover, in a number of studies simple regression analysis was used which is not appropriate when the dependency of a variable (e.g. the volume history) on a series of independent variables is sought. In the present study multiple regression analysis, used to evaluate the effect of each variable independent of the effects of all other variables, was insensitive in demonstrating that the association of the $\mathrm{M} / \mathrm{P}$ ratio with the presence of inflammatory cells or their metabolic product (ECP) was of clinical relevance in patients with mild to moderate asthma.

Indirect evidence of the hypothesis that volume history response during obstruction may be a useful noninvasive index of lung inflammation stems from the observation that the degree of DI reversal is inversely related to BHR [5], a putative index of inflammation. Airway inflammation and BHR are recognized as major characteristics of bronchial asthma. However, their relationship is still poorly understood. Recent morphological and functional studies have shown that BHR may be sustained by airway wall remodelling [32] and an inability to dilate constricted airways [33]. Recently, CRIMI et al. [34] and RoSI et al. [35] were able to demonstrate that BHR is independent of the number of inflammatory cells in the airway lumen or mucosa. The present results, showing the independence among sputum cellular and biochemical profile, volume history and BHR are in line with the results of these studies [34, 35].

According to multiple regression analysis, age explained a significant, though small, percentage of variability in volume history effects. The role of age was not unexpected, possibly reflecting ageing-associated change in parenchymal hysteresis [21].

Finally, the data showing a significant relationship between $\mathrm{FEV} 1 / \mathrm{VC}$ and $\mathrm{M} / \mathrm{P}$ ratio $(\mathrm{p}<0.01)$ are in line with the results of Lim et al. [24] who found that the M/P ratio related to the expression of airway obstruction in spontaneously obstructed asthmatics and was smaller in more obstructed and severely affected patients, compared to less obstructed and less severely affected ones.

In conclusion, it is believed that clinical and functional aspects and sputum expression of the eosinophilic, probably central, inflammatory process should be independently assessed. Further studies looking at different aspects of airway inflammation are needed.

Acknowledgements. The authors thank V. Brusasco for valuable comments and helpful suggestions about the manuscript.

\section{References}

1. Ingram RH. Relationships among airway-parenchymal interactions, lung responsiveness, and inflammation in asthma. Chest 1995; 107: S148-152.

2. Pliss LB, Ingenito EP, Ingram RH. Responsiveness, inflammation, and effects of deep breaths on obstruction in mild asthma. J Appl Physiol 1989; 66: 2298-2304.

3. Lim TK, Ang SM, Rossing TH, Ingram RH. The effects of deep inhalation on maximal expiratory flow during intensive treatment of spontaneous asthmatic episodes. Am Rev Respir Dis 1989; 140: 340-343.

4. Bel EH, Timmers MC, Dijkman JH, Sterk PJ. The longterm of nedocromil sodium and beclomethasone dipropionate on bronchial responsiveness to methacholine in non atopic asthmatic subjects. Am Rev Respir Dis 1990; 141: 21-28.

5. Ingram RH Jr. Site and mechanism of obstruction and hyperresponsiveness in asthma. Am Rev Respir Dis 1987; 136: S62-S64.

6. Ingenito EP, Godleski JJ, Pliss LB, Pichurko BM, Ingram RH. Relationship among mediators, inflammation, and 
volume history with antigen versus hyperpnea challenge in guinea pigs. Am Rev Respir Dis 1992; 146: 1315-1319.

7. Pin I, Gibson PG, Kolendowicz R, et al. Use of sputum cell counts to investigate airway inflammation in asthma. Thorax 1992; 47: 25-29.

8. Fahy JV, Liu J, Wong H, Boushey HA. Cellular and biochemical analysis of induced sputum from asthmatics and from healthy subjects. Am Rev Respir Dis 1993; 147: 1126-1131.

9. Pizzichini E, Pizzichini MMM, Efthimiadis A, Dolovich $\mathrm{J}$, Hargreave FE. Measuring airway inflammation in asthma; eosinophils and eosinophilic cationic protein in induced sputum compared with peripheral blood. $J$ Allergy Clin Immunol 1997; 99: 539-544.

10. Pizzichini E, Pizzichini MMM, Kidney JC, et al. Induced sputum, bronchoalveolar lavage and blood from mild asthmatics: inflammatory cells, lymphocyte subsets and soluble markers compared. Eur Respir J 1998; 11: 828834.

11. National Heart, lung and Blood Institute. International consensus report on diagnosis and management of asthma. Publication No. 92-3091. Bethesda, Maryland 20892, USA: National Heart, Lung and Blood Institute, National Institutes of Health. Eur Respir J 1992; 5: 601-641.

12. Brooks SM, Bernstein L, Raghuprasad PK, Maccia CA, Mieczkowski L. Assessment of airway hyperresponsiveness in chronic stable asthma. $J$ Allergy Clin Immunol 1990; 85: 17-26.

13. Mahler DA, Wells CK. Evaluation of clinical methods for rating dyspnea. Chest 1988; 93: 580-586.

14. Scano G, Garcia Herreros P, Stendardi D, Degre S, De Coster A, Sergysels R. Cardiopulmonary adaptation to exercise in coal miners. Arch Environ Health 1980; 35: 360-366.

15. European Community for Coal and Steel. Standardization of lung function tests. Eur Respir J 1993; 6 (Suppl. 16): $1-100$.

16. Brusasco V, Pellegrino R, Violante B, Crimi E. Relationship between quasi static pulmonary hysteresis and maximal airway narrowing in humans. J Appl Physiol 1992; 72: 2075-2080.

17. Ronchi MC, Piragino C, Rosi E, Amendola M, Duranti R, Scano G. Role of sputum differential count in detecting airway inflammation in patients with chronic bronchial asthma. Thorax 1996; 51: 1-5.

18. Ronchi MC, Piragino C, Rosi E, et al. Do sputum eosinophils and ECP relate to the severity of asthma? Eur Respir J 1997; 10: 1809-1813.

19. Sterk PJ, Fabbri LM, Quanjer PhH, et al. Airway Responsiveness. Eur Respir J 1993; 6 (Suppl. 16): 53-83.

20. Altman DG. Practical statistics for medical research. London, Chapman \& Hall, 1991, pp. 336-351.

21. Sparrow D, O'Connor GT, Weiss ST, DeMolles D, Ingram
$\mathrm{RH}$. Volume history effects and airway responsiveness in middle-aged and older men. Am J Respir Crit Care Med 1997; 155: 888-892.

22. Berry RB, Fairshter RD. Partial and maximal flow volume curves in normal and in asthmatic subjects before and after inhalation of metaproterenol. Chest 1985; 88: 697-702.

23. Pichurko BM, Ingram RH. Effects of airway tone and volume history on maximal expiratory flow in asthma. $J$ Appl Physiol 1987; 62: 1133-1140.

24. Lim TK, Pride NB, Ingram RH. Effects of volume history during spontaneous and acutely induced air-flow obstruction in asthma. Am Rev Respir Dis 1987; 135: 591-596.

25. Froeb HF, Mead J. Relative hysteresis of the dead space and lung in vivo. J Appl Physiol 1968; 25: 244-248.

26. Macklem PT. A theoretical analysis of airway smooth muscle load on airway narrowing. Am J Respir Crit Care Med 1996; 153: 83-89.

27. Pellegrino R, Brusasco V. On the causes of lung hyperinflation during bronchoconstriction. Eur Respir J 1997; 10: 468-475.

28. Freedberg JJ, Inouye D, Miller B, et al. Airway smooth muscle, tidal stretches, and dynamically determined contractile states. Am J Respir Crit Care Med 1997; 156: 1752-1759.

29. Fahy JV, Kim KW, Liu J, Boushey HA. Prominent Neutrophils inflammation in sputum from subjects with asthma exacerbation. J Allergy Clin Immunol 1995; 95: 843-852.

30. Pizzichini E, Pizzichini MMM, Efthimiadis A, et al. Indices of airway inflammation in induced sputum: reproducibility and validity of cell and fluidphase measurements. Am J Respir Crit Care Med 1996; 154: 308-317.

31. Ward C, Gardiner PV, Booth H, Walters EH. Intrasubject variability in airway inflammation sampled by bronchoalveolar lavage in stable asthmatics. Eur Respir J 1995; 8: 1866-1871.

32. Wiggs BR, Bosken C, Parè PD, James A, Hogg JC. A model of airway narrowing in asthma and in chronic obstructive pulmonary disease. Am Rev Respir Dis 1991; 145: 1251-1258.

33. Skloot G, Permutt S, Togias A. Airway hyperresponsiveness in asthma: a problem of limited smooth muscle relaxation with inspiration. J Clin Invest 1995; 96: 23932403.

34. Crimi E, Spanevello A, Neri M, Ind PW, Rossi GA, Brusasco V. Dissociation between airway inflammation and airway hyperresponsiveness in allergic asthma. Am J Respir Crit Care Med 1998; 157: 4-9.

35. Rosi E, Ronchi C, Grazzini M, Duranti R, Scano G. Sputum analysis, bronchial hyperresponsiveness and pulmonary function in asthma: results of a factor analysis. $J$ Allergy Clin Immunol 1999; 103: 232-237. 